\title{
Pasal 9 Konstitusi Jepang: Perubahan Sikap AS Terhadap Militer Jepang
}

\author{
Helsi Eka Putri
}

\author{
Pascasarjana Ilmu Hubungan Internasional, Universitas Indonesia - Indonesia \\ Email: helsieci@gmail.com \\ Diserahkan: 01 Oktober 2018 | Diterima: 15 Desember 2018
}

\begin{abstract}
This article explains the US foreign policy on the Obama administration towards the reinterpretation of article 9 of the Japanese constitution. Historically, article 9 was the result of US interference to keep Japan from proactive military activities and oblige Japan to sacrifice all its territory since 1895, and to incorporate Japan into the US security system. This evoke a question, why in the era of Obama administration US supported article 9 reinterpretation efforts that will make the Japanese military proactive? The purpose of this article is to analyze the direction of US President Barack Obama's foreign policy in the second period. Foreign policy theory with national interest concept approach is used to analyze three factors influencing US foreign policy to support the reinterpretation of article 9. This article uses literature study by collecting data that related to the factors of US in doing such foreign policy towards Japan. Ultimately, this article argued that external, internal, and perceptions of US decision-makers influence US foreign policy in favor of reinterpretation of article 9 .
\end{abstract}

Keywords: Foreign, Policy, Pivot to Asia, US-Japan, Alliance.

\begin{abstract}
Abstrak
Dalam artikel ini dibahas tentang kebijakan luar negeri AS pada pemerintahan Obama terhadap reinterpretasi pasal 9 konstitusi Jepang yang secara historis merupakan hasil intervensi AS untuk menahan Jepang proaktif dalam melaksanakan kegiatan militer dan mewajibkan Jepang untuk mengorbankan semua wilayah yang didudukinya sejak 1895 serta memasukkan Jepang ke dalam sistem keamanan Amerika Serikat. Pertanyaan kemudian adalah mengapa pada era Obama AS mendukung upaya reinterpretasi pasal 9 yang akan membuat militer Jepang kembali proaktif? Artkel ini bertujuan untuk menganalisis politik Luar Negeri AS era Presiden Barack Obama periode kedua. Teori foreign policy dengan konsep national interest digunakan untuk menganalisis tiga faktor yang mempengaruhi kebijakan luar negeri AS terhadap reinterpretasi artikel 9. Dalam artikel ini digunakan studi pustaka untuk memperoleh data dan informasi yang mempengaruhi kebijakan luar negeri AS terhadap Jepang. Tulisan ini berpendapat bahwa faktor eksternal, internal, dan persepsi aktor pengambil keputusan di AS mempengaruhi kebijakan luar negeri AS mendukung reinterpretasi pasal 9 .
\end{abstract}

Kata Kunci: Kebijakan, Luar Negeri, Pivot to Asia, Aliansi, AS-Jepang.

\section{PENDAHULUAN}

Kebijakan luar negeri yang dikeluarkan Amerika Serikat (AS) pada masa Presiden Barrack Obama periode kedua menunjukan perubahan fokus kebijakan luar negeri AS dari Timur
Tengah ke Asia Pasifik. Hal ini diungkapkan langsung oleh Presiden Barack Obama pada pidatonya di Parlemen Australia pada tanggal 17 November 2011 “As we end today's wars, 
I have directed my national security team to make our presence and mission in the Asia Pacific a top priority" (The White House Office of the Press Secretary, 2011) di mana perubahan ini dikarenakan adanya pengaruh sistem internasional, kondisi, dan juga dinamika yang sedang terjadi di Asia Pasifik (Foreign Policy, 2018). Asia Pasifik merupakan bagian dari fokus utama AS di bidang politik, ekonomi, serta militer. Dalam sebuah kebijakan luar negeri yang dikeluarkan oleh AS yaitu "Pivot to Asia”, yang menandakan awal perubahan prioritas kebijakan luar negeri AS dari Timur Tengah ke Asia Pasifik (Quinn, 2013).

Dalam menyatakan niatnya pada 2011 untuk "pivot" yang lebih intensif terhadap Asia-Pasifik, pemerintahan Obama mengedepankan tiga poin utama untuk mengatur upaya ini. Pertama, pivot ke Asia ini dimaksudkan untuk menjadi demonstrasi komitmen pemerintahan Obama yang menginginkan berakhirnya konflik di Afghanistan dan Irak dan memberikan prioritas yang lebih besar untuk fokus pada kekuasaan dan sumber daya AS terhadap wilayah Asia-Pasifik yang dinamis. Kedua, pemerintahan Obama menyajikan kasus strategis secara rinci pada pentingnya Asia-Pasifik untuk kepentingan kebijakan jangka panjang dalam dan luar negeri Amerika Serikat. Ketiga, rencana ini diajukan untuk memperkuat pengaruh Amerika di kawasan tersebut melalui pendalaman interaksi ekonomi, keterlibatan diplomatik yang lebih besar, upaya kuat untuk mempromosikan hak asasi manusia dan demokratisasi, dan memperkuat kehadiran militer AS. "The Pivot", atau yang lebih diketahui, "rebalance" terhadap Asia-Pasifik menjadi salah satu kebijakan luar negeri pemerintahan Obama yang paling menonjol (Gill, 2016).

\section{PERUBAHAN KEBIJAKAN LUAR NEGERI AMERIKA SERIKAT (AS) ERA PRESIDEN OBAMA}

Kebijakan luar negeri AS secara resmi diarahkan seluruh wilayah Asia Pasifik yang mencakup wilayah Pasifik dan Samudra Hindia. Kebijakan tersebut diarahkan untuk membendung pertumbuhan China oleh AS. AS juga menginisiasi Trans Pacific Partnership tanpa kehadiran China di dalamnya dalam upaya kerjsama perdagangan. Hillary Clinton secara terbuka mengakui bahwa salah satu yang paling menonjol di kawasan Asia-Pasifik tentu saja China, tetapi Hillary Clinton menolak pandangan bahwa "US pivot" terhadap Asia Pasifik diarahkan untuk membatasi China, dengan menyatakan bahwa "Kami (AS dan China) akan menghasilkan lebih banyak keuntungan dari kerjasama daripada konflik" (Clinton, 2011). 
Pada ranah strategis, Amerika Serikat ingin Asia Tenggara untuk membentuk pusat "Asian Strategic Alliance" yang mencakup Asia Timur Laut, Asia Tenggara dan India. Pada tingkat politik, AS terus mengekspor "Demokrasi" dan nilai-nilai Barat ke negara-negara Asia Tenggara. Pada tingkat ekonomi, AS memiliki hubungan dekat dengan Asia Tenggara dalam hal perdagangan, keuangan dan investasi. Pada tingkat militer dan keamanan, AS ingin mendirikan pangkalan militer dan lebih positif mencampuri urusan keamanan di kawasan Asia-Pasifik. Sejak pengumuman poros AS ke Asia, Pertahanan Amerika Serikat telah menggeser sebagian besar asset angkatan laut ke wilayah Asia Pasifik pada tahun 2020, serta meningkatkan latihan militer dan hubungan di wilayah tersebut. Dalam proses ini, persaingan maritim di Laut China Selatan terus dipercepat (Steinbock, 2015).

Seiring dengan berjalannya pivot to Asia dan dalam rangka penguatan pengaruh AS di Asia-Pasifik dalam bidang militer, pada tanggal 3 Oktober 2013, AS dan Jepang mengeluarkan "Joint Statement of the Security Consultative Committee: Toward a More Robust alliance and Greater Shared Responsibilities." (Minister for Foreign Affairs Kishida, 2013). Di dalam dokumen tersebut, AS "menyambut" niat dari Pemerintahan
Abe tentang "re-examining the legal basis for its security including the matter of exercising its right of collective selfdefense...". Dengan kata lain, menemukan cara untuk merubah interpretasi dari pasal 9 yang kemudian dapat memungkinkan Jepang untuk mengambil kebijakan militer yang lebih ofensif dan tidak menghalangi partisipasinya dalam perang agresi (Wright, 2013). Setelah keluarnya perjanjian ini, 27 April 2015, Jepang dan AS menandatangani kerjasama keamanan baru yang menempatkan Jepang pada posisi yang legih agresif dalam pergolakan keamanan global sebagai pendukung AS. Sebagai imbalannya AS memberikandukungan politik dan keamanan yang lebih kuat kepada Jepang.

Dengan disahkannya perjanjian Joint Statement of the Security Consultative Committee: A Stronger Alliance for a Dynamic Security Environment The New Guidelines for U.S.Japan Defense Cooperation dan suksesnya kebijakan Jepang untuk mereinterpretasikan konstitusinya terkait self-defense Jepang yang tertulis pada article 9 mengisyaratkan bahwa AS mengambil sikap mendukung terhadap keinginan Jepang untuk mereinterpretasi pasal 9 agar Jepang dapat bergerak secara proaktif dalam bidang militer. Hal ini secara tertulis diungkapkan dalam perjanjian tersebut: 
'Japan's security policy continues to reflect its long-standing commitment to regional and global peace and stability, as well as its intention to make more proactive contributions to addressing the challenges faced by the international community. At the same time, Japan will continue coordinating closely with the United States to expand its role within the framework of the U.S.- Japan Alliance. Japan is also preparing to establish its National Security Council and to issue its National Security Strategy. In addition, it is re-examining the legal basis for its security including the matter of exercising its right of collective self-defense, expanding its defense budget, reviewing its National Defense Program Guidelines, strengthening its capability to defend its sovereign territory, and broadening regional contributions, including capacitybuilding efforts vis-à-vis Southeast Asian countries. The United States welcomed these efforts and reiteratedits commitment to collaborate closely with Japan" (Minister for Foreign Affairs Kishida M.O, 2015).

Reinterpretasi pasal 9 merupakan hasil dari diskusi yang panjang dan juga melibatkan banyak pihak. Dengan adanya reinterpretasi article nine, Jepang secara besar merubah banyak hal terkait militer maupun sistem pertahanan. Berikut merupakan hasil dari diskusi panel mengenai reinterpretasi pasal 9:

"The provision of paragraph 1 of Article 9 should be interpreted as probibiting the threat or the use of force as means of settling international disputes to which Japan is a party. The provisions should be interpreted as not probibiting the use of force for the purpose of self-defense, nor imposing any constitutional restrictions on activities that are consistent with international law. The provision of the paragraph 2 of Article 9 should be interpreted as stipulating that "in order to accomplish the aim of the preceding paragraph," war potential will never be maintained. The paragraph should therefore be interpreted as not prohibiting the maintenance of force for other purposes, namely self-defense or so-called international contributions to international efforts" (Yanai, 2008).

Pada bulan Juli 2014 Kabinet Abe mengumumkan hasil reinterpretasi Artikel 9 yang menyatakan bahwa Jepang dapat melindungi negara lain dengan 3 syarat: pertama, jika negara yang dekat atau beraliansi dengan Jepang mengalami serangan militer yang mengancam ketahanan Jepang dan menimbulkan bahaya yang fundamental bagi hak untuk hidup, kebebasan, dan kebahagiaan. Kedua, ketika tidak ada cara lain untuk menangkal serangan dan menjamin keselamatan Jepang dan rakyatnya. Ketiga, ketika Jepang membatasi penggunaan kekuatan sampai batas minimum yang diperlukan (Traphagan, 2012).

Hal ini cukup aneh karena setelah akhir Perang Dunia II, konstitusi Jepang yang sebagian ditulis oleh Amerika Serikat untuk bangsa Jepang yang kalah, menolak perang sebagai solusi dari adanya konflik dan 
menyerahkan keamanan nasionalnya ke tangan sekutunya yaitu AS (Wright, 2013). Konstitusi tersebut telah ditetapkan pada tanggal 3 Mei 1947. Kekalahan Jepang pada PD II mengakibatkan negara ini harus menerima Konstiusi Meiji 1889 digantikan dengan Konstitusi 1947 yang dibuat oleh campur tangan 24 pengacara AS di bawah ketua Charles Louis Kades atas kuasa dari Jendral McArtur. Hal ini adalah upaya AS untuk menahan Jepang melakukan kegiatan militer yang proaktif dan mewajibkan Jepang untuk mengorbankan semua wilayah yang didudukinya sejak 1895, serta memasukkan Jepang ke dalam sistem keamanan Amerika Serikat. Amerika Serikat menandatangani perjanjian berikutnya dengan Jepang pada tahun 1954 yang isinya adalah menyediakan perlengkapan-perlengkapan, alat-alat, dan lainnya bagi Jepang. Sebaliknya Jepang menyediakan basis-basis militer dan alat-alat yang diperlukan oleh Amerika Serikat (Emmerson, 1971).

Melihat dari fenomena di atas dan seiring dengan adanya perubahan fokus kebijakan luar negeri AS kearah Asia-Pasific, AS justru mendukung Jepang untuk meningkatkan militernya menjadi lebih proaktif, sehingga untuk mencapai hal tersebut Jepang harus mereinterpretasi isi pasal 9 dalam konstitusi negaranya yang melarang Jepang untuk bertindak secara proaktif dalam bidang militer. Sangat menjadi pertanyaan terkait sikap AS yang sekarang malah mendukung adanya mereinterpretasi pasal 9. Padahal pasal 9 dalam konstitusi Jepang dibuat berdasarkan adanya intervensi AS pada pasca perang dunia II untuk membuat militer Jepang menjadi pasif. Artikel ini menjelaskan kebijakan luar negeri AS terhadap reinterpretasi pasal 9 dengan menggunakan pendekatan konsep national interest.

\section{TINJAUAN LITERATUR}

Perdebatan yang berkembang dalam berbagai literatur secara garis besar membahas masalah ini dari sudut pandang Jepang. Para ahli dan akademisi sebelumnya menjelaskan faktor-faktor dan motivasi Pemerintahan Abe melakukan reinterpretasi pasal 9. Salah satu alasan reinterpretasi pasal 9 adalah adanya pengaruh tekanan yang cukup besar dari AS (Richter, 2016). Selain itu, Funaiole mencoba melihat hal ini melalui teori identitas negara. Penelitian ini menjelaskan bahwa reinterpretasi pasal 9 merupakan strategi mobilitas sosial Jepang yang telah ada dan berjalan konsisten sejak masa pemerintahan perdana Menteri Koizumi. Terjadinya pergeseran dinamika kekuasaan regional yang mengarah ke China menekan para pemimpin Jepang untuk 
mempertahankan kekuatan dan Prestise Regional Jepang (Funaiole, 2015).

Mayumi Itoh menjelaskan dengan adanya reinterpretasi pasal 9 setidaknya ada 3 keuntungan penting yang akan didapatkan Jepang. Pertama, revisi pasal 9 merupakan prasyarat bagi Jepang untuk menjadi bangsa yang benar-benar independen dan percaya diri. Kedua, mengartikulasikan hak untuk membela diri secara kolektif dalam konstitusi akan menghilangkan ambiguitas yang telah menghambat langkah apapun untuk memperkuat hubungan keamanan AS-Jepang. Ketiga, penegasan hak Jepang untuk terlibat dalam kegiatan bela diri kolektif juga akan menghapus alasan legalistik yang telah mencegah SelfDefence Forces (SDF) untuk berpartisipasi secara aktif dalam operasi pemeliharaan perdamaian (peacekeeping operations) (Itoh, 2001).

Literatur lainnya menegaskan adanya upaya kolektif dari AS dan Jepang untuk memperkuat aliansi mereka dikarenakan ketegangan dan ketidakstabilan yang meningkatdi Asia Timur Laut (Rowberry, 2014). Ancaman-ancaman tersebut menimbulkan tekanan terhadap pemerintahan Abe untuk lebih proaktif secara militer. Dari berbagai penjelasan di atas, secara garis besar Jepang dipojokan dengan keadaan dan adanya dorongan dari AS. Namun, pertanyaan lain yang muncu dengan adanya hal ini adalah tindakan AS yang mendukung reinterpretasi pasal 9 konstitusi Jepang yang secara historis disusun atas intervensi AS.

Dari berbagai literatur yang telah ada, sangat sedikit yang melihat pentingnya untuk menyoroti kebijakan luar negeri AS yang secara historis turut membentuk pasal 9. Penulisakan berfokus untuk melihat hal ini dari sudut pandang AS. Untuk melihat tindakan yang dilakukan oleh AS maka penulis menyoroti pentingnya untuk melihat kebijakan AS ini dari 3 faktor yang mendasari kebijakan luar negeri suatu negara. Penulis menggunakan teori foreign policy dengan pendekatan konsep national interest yang akan melihat fenomena ini secara lebih dalam.

\section{FOREIGN POLICY THEORY DAN KONSEP NATIONAL INTEREST}

Untuk menjelaskan permasalahan di atas, penulis akan menggunakan foreign policy analysis dengan pendekatan konsep national interest. Foreign policy analysis dinilai mampu menjelaskan secara garis besar tentang kebijakan luar negeri suatu negara. Sedangkan, pendekatan konsep national interest ini dinilai mampu untuk menjelaskan dan menganalisis kebijakan luar negeri AS yang mendukung reinterpretasi pasal 9 konstitusi Jepang.

Menurut K. J. Holsti, kebijakan 
luar negeri adalah suatu tindakan atau ide yang dirancang oleh para pembuat kebijakan untuk mencegah suatu masalah atau melancarkan perubahan dalam lingkungan, yaitu dalam kebijakan, sikap atau tindakan suatu negara. Meskipun, beberapa kebijakan dibuat untuk mengubah kondisi luar negeri demi meraih kepentingan negara pembuat kebijakan. Kebanyakan kebijakan tersebut dibuat demi kepentingan dalam negeri, seperti mencari rasa aman, kesejahteraan, otonomi dan gengsi (Holsti, 1987).

Berikut 3 faktor yang melatarbelakangi perumusan kebijakan luar negeri menurut Holsti: 1. Faktor eksternal seperti: sistem internasional, kebijakan dan tujuan negara lain, masalah global dan regional, hukum internasional serta opini dunia; 2. Faktor domestik seperti: kepentingan nasional baik kepentingan sosial, ekonomi dan keamanan; 3. Faktor dari pengaruh persepsi dan perilaku para aktor pembuat kebijakan (Holsti, 1987).

Faktor eksternal juga dapat diartikan sistem internasional ataupun masalah global yang berupa suatu ancaman yang harus ditangani dengan kebijakan luar negeri. Faktor domestik berkaitan erat dengan kepentingan nasional suatu negara yang meliputi faktor ekonomi maupun keamanan. Faktor ketiga yaitu hal-hal yang berkaitan dengan aktor-aktor yang terlibat, yang berarti dalam menganalisa kebijakan luar negeri kita harus turut melihat aktor sebagai pembuat keputusan.

Pendapat lain dari Mark R. Amstutz mendefinisikan kebijakan luar negeri sebagai "foreign policy as explicit and implicit actions of governmental officials designed to promote national interest beyond a country's territorial boundaries" (Amstutz, 1998). Sependapat dengan Mark, Valerie M. Hudson mendefinisikan kebijakan luar negeri sebagai strategi atau pendekatan yang dipilih oleh pemerintah nasional untuk mencapai tujuannya dalam hubungannya dengan entitas luar, termasuk keputusan untuk tidak bertindak (Steve Smith, 2012). Sebagai komponen dalam pembuatan kebijakan luar negeri, Graham T. Allison menyebutkan bahwa: "National security and national interest are the principal categories in which strategic goals are conceived" (Allison, 1971). Di sini ditegaskan bahwa kepentingan nasional merupakan hal terpenting dalam memahami arah tujuan suatu kebijakan luar negeri. Pendapat lain mengatakan bahwa kepentingan nasional merupakan tujuan dari negara yang kemudian diwujudkan dalam kebijakan luar negeri "National interest as a guide to foreign policy" (Martin Griffiths, 2008).

Kepentingan nasional dapat dikategorikan menjadi dua kategori 
mendasar yaitu; kepentingan nasional yang bersifat vital atau esensial dan kepentingan nasional yang bersifat non-vital atau sekunder. Kepentingan nasional yang bersifat vital biasanya berkaitan dengan kelangungan hidup negara tersebut serta nilai-nilai inti (core values) yang menjadi identitas kebijakan luar negerinya. Sedangkan kepentingan nasional non-vital atau sekunder tidak berhubungan secara langsung dengan eksistensi negara itu namun tetap diperjuangkan melalui kebijakan luar negeri. Kepentingan vital menjelaskan seberapa jauh kepentingan tersebut ada dan digunakan, di mana lebih kepada keadaan darurat suatu negara sehingga harus segera diputuskan. Berbeda dengan kepentingan non-vital yang digunakan karena prosesnya berlangsung lama namun hasilnya dan fungsinya dapat dirasakan lebih baik dikemudian hari dengan jangka waktu yang lama (Jemadu, 2008).

\section{Operasionalisasi Konsep}

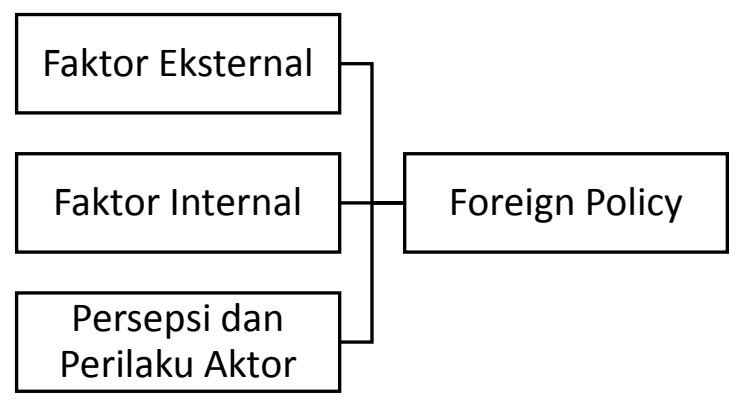

\section{Model Analisis}

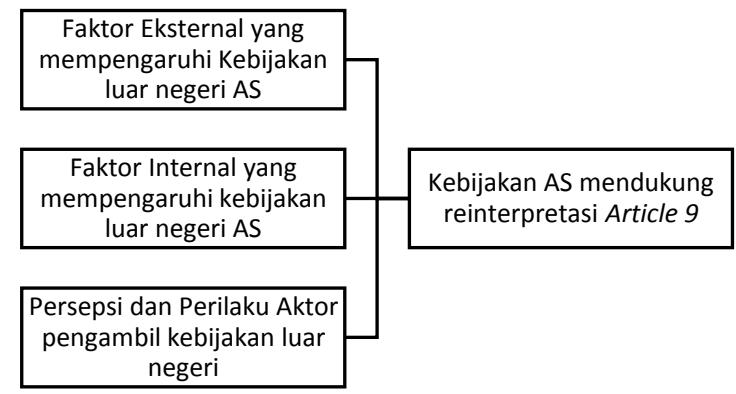

ANALISIS DAN PEMBAHASAN Faktor Eksternal yang Mendorong AS Mendukung Reinterpretasi Artikel 9

Kebijakan luar negeri AS yang mendukung reinterpretasi pasal 9tidak luput dari adanya pengaruh eksternal. Pengaruh ini merupakan adanya perubahan sistem internasional yang mengharuskan AS untuk mengambil tindakan guna melindungikepentingan nasionalnya. Salah satu faktor tersebut adalah dinamika dan ancaman keamanan di kawasan Asia Timur, antara lain peningkatan militer Tiongkok dan ancaman nuklir Korea Utara.

Seperti yang dikatakan Obama dalam kunjungannya ke Parlemen Australia bahwa "The transfer of nuclear materials or material by North Korea to states or non-state entities would be considered a grave threat to the United States and our allies, and we would hold North Korea fully accountable for the consequences of such action (Secretary, Speeches \& Remarks, 2011). Dari pernyataan Obama tersebut terlihat bahwa AS 
menganggap Korea Utara dan aktifitas peningkatan nuklirnya sebagai ancaman bersama bagi AS dan sekutusekutunya. Dengan adanya ancaman nuklir Korea Utara, keamanan dan kestabilan kawasan akan terganggu. Hal ini akan menimbulkan security dilemma bagi negara-negara tetangga Korea Utara dan juga AS. Kecemasan AS terhadap pengembangan nuklir Korea Utara bukan tanpa sebab yang jelas. Ancaman ini bukan hanya sebatas militer, namun akan berdampak pada banyak hal, antara lain aktifitas ekonomi AS di wilayah Asia Pasifik. Ancaman lainnya datang dari Cina dengan perkembangan militer yang pesat. Dimulai dengan sikap agresif China yang ditunjukan pada sengketa Laut China Selatan maupun kasus ADIZ dengan Jepang dan juga peningkatan anggaran belanja militer yang cukup signifikan selama beberapa tahun terakhir. Berikut data peningkatan anggaran pertahanan China 2008-2015.

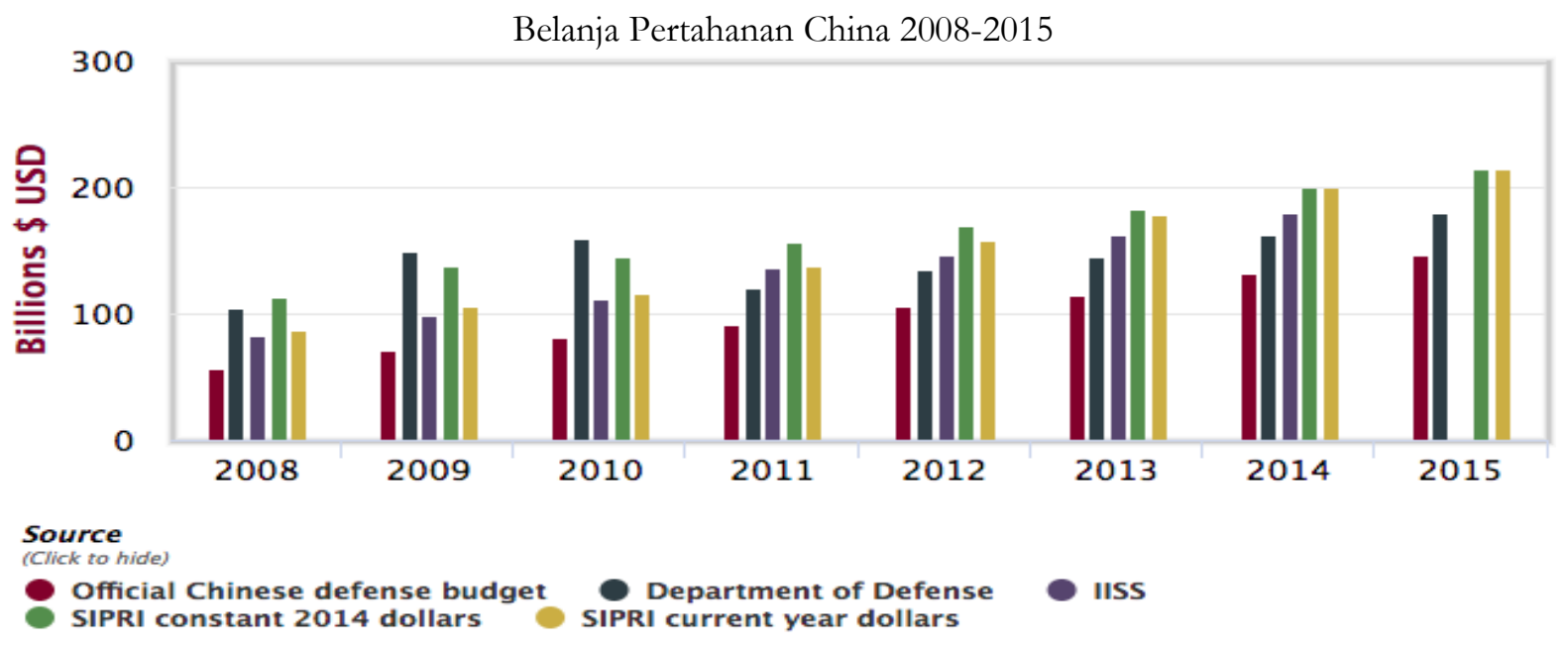

Sumber: CSIS China Project

(www.chinapower.csis.org)

Data diatas menunjukan peningkatan belanja pertahanan Cina mulai tahun 2012 sampai tahun 2015. Pada tahun 2010, Cina merupakan negara kedua yang memiliki anggaran militer terbesar. Dalam jangka waktu dari 2001-2010 China mengalami peningkatan belanja militer sebanyak $189 \%$.
Gambar 2

Jumlah personel militer negara Asia Pasifik

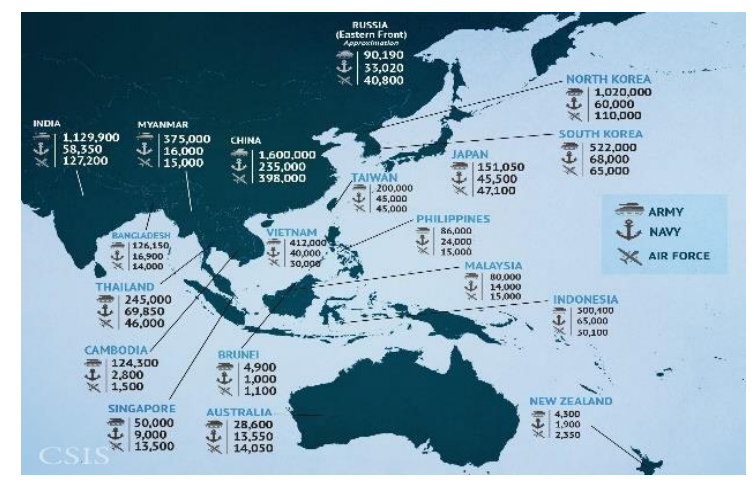


Selain anggaran militer yang terus meningkat, China juga memiliki jumlah personel militer terbanyak di kawasan Asia. Dapat dilihat pada gambar di atas, angkatan darat China berjumlah 1.6 juta personel, 235 ribu personel angkatan laut, dan 398 personel angkatan udara. Total keseluruhan personel militer China adalah 2.233.000 orang. Jumlah tersebut sangat jauh dibandingkan dengan negara-negara sekelilingnya, contohnya Jepang dengan total keseluruhan personel 243.650. Peningkatan anggaran pertahanan yang sebagian besar dihabiskan untuk belanja militer China menimbulkan respon sekitarnya untuk turut meningkatkan pertahanan sebagai bentuk counter balance dalam menghadapi peningkatan militer China. Hal ini menimbulkan ketegangan antar kawasan yang akan mempengaruhi kestabilan aktifitas lain terutama kegiatan perdagangan AS di kawasan Asia Pasifik.

Merespon hal ini, AS memperkuat aliansi dengan Jepang sebagai upaya AS untuk meredam kekuatan China di Asia Pasifik. Hal ini juga dilakukan untuk meredam hegemoni China yang mulai terlihat menonjol di kawasan Asia Pasifik. Seperti yang dikatakan Obama "The United States and its economic and security partners in the region have all been pursuing a hedging strategy of cooperation with China on issues where interests overlap (especially economically), yet seeking to counterbalance Beijing's growing military capacity and influence" (Manning, 2014). Dari pernyataan Obama tersebut, terlihat bahwa AS melakukan upaya untuk mengimbangi pertumbuhan kekuatan China dengan cara memperkuat kerjasama dengan negara aliansi dalam bidang ekonomi dan juga keamanan.

\section{Faktor Internal yang Mendorong AS Mendukung Reinterpretasi Artikel 9}

Keinginan AS untuk menjaga stabilitas keamanan kawasan Asia dan juga banyaknya kepentingan AS di kawasan tersebut mendorong AS untuk mencari cara untuk mengimbangi kekuatan militer apapun yang tumbuh di kawasan tersebut. AS melihat peningkatan militer yang dilakukan oleh Tiongkok dan juga Korea Utara dapat mengancam kepentingan nasionalnya di kawasan Asia. Jepang dan AS melihat Korea Utara sebagai ancaman jangka pendek, namun lebih khawatir terhadap meningkatnya militer China (Manning, 2014).

Alasan keamanan di atas merupakan faktor ekternal yang mendorong AS mendukung Jepang untuk melakukan reinterpretasi pasal 9. Faktor internal datang dari dalam negeri AS, faktor ini erat kaitannya dengan kepentingan nasional AS yang 
ingin dicapai melalui kebijakan luar negerinya tehadap Jepang. Dengan adanya reinterpretasi pasal 9 konstitusi Jepang maka Jepang dapat bergerak secara lebih proaktif dalam bidang militer.

Dengan berubahnya militer Jepang menjadi lebih proaktif dapat menguntungkan AS karena Jepang dapat menjadi extended deterrence bagi AS di wilayah Asia Pasifik. Selain itu, pertahanan AS menjadi lebih kuat karena jika terjadi serangan terhadap negara lain yang berhubungan erat dengan Jepang, maka Jepang dapat melakukan intervensi militer untuk membantu negara tersebut (Traphagan, How Japan Sees its Military, 2012). Hal ini sangat menguntungkan AS karena jika terjadi serangan terhadap AS, maka Jepang dapat membantu secara militer. Hal ini juga diungkapkan dalam Congressional Research Service:

"these bilateral and multilateral links among U.S. allies and partners as beneficial to U.S. security interests by both enhancing deterrence and perbaps lessening the sense of direct rivaly with potential adversaries. Japan'smilitary, called the Japan Self Defense Forces (SDF), will be legally permitted to help defend the United States (or another country) if it comes under attack and that attack threatens Japan” (Emma, 2015).

Selain itu, dengan adanya extended deterrence AS di wilayah Asia Pasifik dengan aliansinya dengan Jepang, maka AS dapat dengan aman menjalankan aktifitas perdagangannya yang melewati jalur pasifik. Perdagangan bebas merupakan fokus AS pada masa kepemimpinan Obama. Dapat dilihat melalui Trans Pasific Partnership yang dicanangkan AS sebagai media perdagangan AS dan negara-negara Asia Pasifik. Dengan keadaan keamanan kawasan yang aman dan stabil akan turut mengamankan aktivitas perdagangan AS di kawasan Asia Pasifik.

Hal lain yang perlu dipertimbangkan adalah sebuah doktrin yang berpengaruh di AS, yaitu Wolfowitz doctrine. Doktrin ini merupakan basis dari kebijakan luar negeri AS untuk melindungi status Uni-power AS semenjak runtuhnya Uni Soviet. Doktrin ini berbunyi:

"Our first objective is to prevent the reemergence of a new rival, either on the territory of the former Soviet Union or elsewhere, that poses a threat on the order of that posed formerly by the Soviet Union. This is a dominant consideration underlying the new regional defense strategy and requires that we endeavor to prevent any hostile power from dominating a region whose resources would, under consolidated control, be sufficient to generate global power" (Roberts, 2015).

Selain itu, Council of Foreign Relations memperluas doktrin ini ke dalam hubungannya dengan China. 
Faktor finansial juga merupakan salah satu dorongan internal AS untuk mendukung reinterpretasi pasal 9 . Pada masa Obama, prioritas anggaran militer berfokus pada biaya relokasi fasilitas militer AS dari Okinawa ke Guam, sehingga mengharuskan AS untuk memotong anggaran aliansi (Emma Chanlett-Avery I. E., 2016). Dengan mendukung reinterpretasi pasal 9 maka AS secara tidak langsung mengurangi beban anggaran aliansi dan dapat lebih berfokus untuk menyelesaikan masalah relokasi fasilitas militer AS ke Guam.

\section{Faktor Persepsi Pengambilan Kebijakan mendukung Pasal 9}

Paham liberalisme pada masa kepemimpinan Obama mempengaruhi kebijakan luar negeri AS. Barack Obama menunjukan identitas AS sebagai negara liberal internationalist. Identitas ini yang akhirnya menjadi arah kebijakan dan respon AS terhadap dinamika global.

\section{Liberal internationalism memiliki} ciri-ciri seperti mendukung perdagangan bebas, institusi internasional, kerjasama keamanan, collective problem solving, dan mengikuti hukum yang berlaku (Ikenberry, 2009). Jika dilihat dengan ciri-ciri di atas, maka identitas AS pada pemerintahan Obama membentuk arah kebijakan luar negeri AS yang lebih menegaskan identitasnya sebagai negara liberal internationalism. Tidakan AS yang paling menunjukan identitasnya sebagailiberal internationalism adalah perubahan fokus kebijakan luar negeri AS dari Timur Tengah ke Asia Pasifik yang lebih dikenal sebagai pivot to Asia. "Pivot" atau yang diketahui sebagai "rebalance" di Indo-Pasifik menjadi salah satu dari kebijakan luar negeri Pemerintahan Obama yang paling menonjol.

Salah satu ciri negara liberal insternasionalist adalah kerjasama keamanan demi terciptanya collective problem solving. Hal ini jelas terlihat dengan sikap AS yang mendukung reinterpretasi pasal 9 agar dapat memperkuat aliansinya dengan Jepang. Dengan terciptanya aliansi yang lebih kuat akan memperkuat keamanan kawasan yang pada akhirnya akan mendorong perdagangan bebas yang lebih maju. Diperkuatnya aliansi dengan Jepang juga merupakan salah satu bentuk collective problem solving untuk mengimbangi kekuatan Chinadi kawasan dengan bekerjasama secara kolektif dengan negara-negara Asia Pasifik.

Selain itu, Obama mengedepankan soft diplomacy dalam segala kebijakan luar negerinya. Dengan adanya Jepang sebagai kekuatan militer yang berkembang di kawasan dapat mencegah hegemoni China di Asia Pasifik atau setidaknya menyeimbangkan kekuatan militer di Asia Pasifik agar terciptanya situasi 
keamanan yang stabil. Dengan jalan ini, AS tidak perlu melakukan intervensi yang bersifat ofensif seperti yang banyak dilakukan pada masa pemerintahan Bush yang mengedepankan hard diplomacy dan banyak melakukan intervensi yang bersifat ofensif seperti yang dilakukan AS di Irak.

\section{KESIMPULAN}

Kebijakan luar negeri AS yang mendukung reinterpretasi pasal 9 konstitusi Jepang dipengaruhi oleh 3 faktor yaitu faktor eksternal, faktor internal, dan persepsi aktor pengambil kebijakan. Faktor eksternal yang mempengaruhi AS mengambil kebijakan ini adalah ketidakstabilan keamanan kawasan yang disebabkan oleh The Rise of China sehingga mendorong AS untuk menyetujui reinterpretasi pasal 9 yang akan membuat Jepang menjadi lebih proaktif secara militer yang diharapkan menjadi extended deterrence AS di Asia Pasifik yang akan menangkal adanya hegemoni China di kawasan agar terciptanya kedamaian di Asia Pasifik. Faktor internal yaitu kepentingan nasional AS untuk menjaga jalur perdagangannya di kawasan Asia Pasifik. Selain itu, kebijakan ini sesuai dengan soft diplomacy yang dianut Obama, dengan terciptanya aliansi yang lebih kuat dengan Jepang maka AS tidak perlu melakukan strategi yang ofensif dalam mengatasi pertumbuhan China di Kawasan Asia.

Teori kebijakan luar negeri dari J. Holsti masih sangat relevan dengan fenomena yang terjadi saat ini. Teori ini melihat 3 aspek dalam pengambilan keputusan yaitu faktor eksternal, internal, dan aktor pengambil kebijakan. Ketiga faktor tersebut sangat tepat untuk menjelaskan mengapa negara mengambil suatu kebijakan luar negeri dengan melihat dari semua aspek yang terkait yang sangat tepat untuk digunakan dalam menganalisa kebijakan luar negeri suatu negara.

\section{REFERENSI}

Allison, G. T. (1971) Essence of Decision : Explaning the Cuban Misile Crisis. Boston: Little, Brown and Company.

Amstutz, M. R. (1998) International Conflict and Cooperation: an Introduction to World Politics, McGraw Hill, hlm. 175.

Art, R. J. (2003) A Grand Strategy for America, Washington D.C: United States Institute of Peace Press.

Emma Chanlett-Avery, Manyin, M. E. (2015) Japan-U.S. Relations: Issues for Congress, Congressional Research Service.

Emma Chanlett-Avery, Rinehart, I. E. (2016) The U.S.-Japan Alliance, Congressional Research Service.

Emmerson, J. K. (1971) Arms, Yen, and Power: The Japan Dillemma. Tokyo: Charles E. Tuttle Company.

Foreign Policy. (2018) Here's Why Asia Pivot Was Barack Obama's Biggest Mistake (Online). Tersedia di: 
http:/ / foreignpolicyi.org/heres-whyasia-pivot-was-barack-obamasbiggest-mistake/ (Diakses: 28 April 2018).

Funaiole, M. P. (2015) “Conceptualizing Japan's Foreign Policy Trajectory Through Social Identity Theory", East Asia: An International Quarterly, 32(4), pp. 361-383.

Holsti, K. J. (1987). Politike Internasional: Suatu Kerangka Analisa. Jakarta: Pedoman Ilmu Jaya.

Ikenberry, J. (2009) "Liberal Internationalism 3.0: America and the Dilemmas of Liberal World Order", Perspective on Politics, 7(1), pp. 71-87.

Itoh, M. (2001) "Japanese Constitutional Revision: A Neo-liberal Proposal for Article 9 in Comparative Perspective", Asian Survey, 41(2), pp. 310-327.

Jemadu, A. (2008) Politik Global dalam Teori dan Praktik, Yogyakarta: Graha Ilmu.

Kishida, M. O. (2013) Toward a More Robust Alliance and Greater Shared Responsibilities (Online). Tersedia di: www.mod.go.jp/e/d_act/us/pdf/Join tStatement2013.pdf (Diakses: 17 Oktober 2018).

Kishida, M. O. (2015) A Stronger Alliance For A Dynamic Security Environment, The New Guidelines for Japan-U.S. Defense Cooperation (Online). Tersedia di: http://www.mod.go.jp/e/d_act/anpo /js20150427e.html (Diakses: 17

Oktober 2018).
Manning, R. A. (2014) The Future of US Extended Deterrence in Asia to 2025, Washington D.C: Atlantic Council.

Martin Griffiths, T. O. (2008). International Relations: The Key Concepts (2nd edition), New York: Routledge.

Quinn, A. (2013) US Pivot To Asia Between Continuity And Change, Assignment Coversheet. Birmingham: University of Birmingham.

Richter, J. P. (2016) “Japan's "Reinterpretation" of Article 9: Pyrrhic Victory for American Foreign Policy?", Iowa Law Review, 3(101), pp. 1223-1262.

Roberts, P. C. (2015) War Threat Rises as Economy Declines (Online). Tersedia di: https://www.foreignpolicyjournal.co $\mathrm{m} / 2015 / 05 / 12 /$ war-threat-rises-aseconomy-declines/ (Diakses: 20 Desember 2017).

Secretary, T. W. (2011) Remarks By President Obama to the Australian Parliament, Initiatives (Online). Tersedia di: https://amti.csis.org/atlas/ (diakses 20 November 2016). 